the combined study of handwriting and psychology. I have been practising as a professional graphologist for some eight years. My special interest has been in researching the parental handwritings of a subject and his own handwritings back to childhood. Unfortunately this meticulous method is not suitable for work on a large scale.

It is my ambition to work for and subordinate to a psychiatrist or a department in a mental hospital or psychiatric clinic. I hope that there will be one or two psychiatrists reached by this letter who would like to take up this offer. If a bona fide enquirer who would be in a position to collaborate with me wished for some demonstration of competence, I should be very happy to provide a graphological analysis of a specimen letter, either of his own or of someone well known to him.

25, Belsize Crescent,

Mary Cecil. (Miss)

London, N.W.3.

\section{MENTAL HEALTH RESEARCH FUND} FELLOWSHIPS

Dear Sir,

I am writing to draw your readers' attention to the Research Fellowships offered each year by the Mental Health Research Fund. Advertisements for these Fellowships, which are for full-time research for up to 5 years at a salary between $£ 1,250$ and $£ 3,000$, are currently appearing in the medical press. Further details may be obtained from this Fund.

J. M. TANNer.

Mental Health Research Fund,

38 Wigmore Street,

London, WIH ${ }_{9} D F$

THE CLINICAL TUTORS' READING LIST IN PSYCHIATRY

DeAr Sir,

A reading list of useful journal articles was included with the February Joumal Supplement, but this was sent to members of the Association only. This list, compiled by the Clinical Tutors Sub-Committee, is now available to everybody, price $1 /-$ (15d) including postage from the R.M.P.A., Chandos House, 2, Queen Anne Street, London, W.1.

The editors of the reading list would like to receive criticism from users, as it is intended to revise the list from time to time and to make it as useful as possible.

T. Ferguson Rodger.

Glasgow University Department of Psychological Medicine, Southern General Hospital,

Glasgow, S.W.I.

\section{THE INTERNATIONAL GLOSSARY OF} ANTICONVULSANTS

Dear Sir,

The Epilepsy Literature Project, under the sponsorship of the International Bureau and the International League Against Epilepsy, has been compiling an International Glossary of Anticonvulsants. Registrants at the World Congress of Neurological Sciences in New York in September, 1969, received a preliminary edition.

Copies of the Glossary are available at no charge and may be obtained by request to:

Mrs. Ellen R. Grass, President

International Bureau for Epilepsy

77 Reservoir Road

Quincy, Massachusetts 02170 , U.S.A.

It will be much appreciated if the readers will tell us of any omissions or errors in the Glossary so that future editions can be revised.

Morton D. Kramer.

Member, Anticonvulsant Glossary Committee.

Department of Neurophysiology, Electroencephalography Laboratory, University of Maryland Hospital,

Redwood and Greene Streets,

Baltimore, Maryland 21201. 